\title{
Correction to: Foreign ownership and corporate excess perks
}

\author{
Lifang Chen ${ }^{1}$, Minghui Han², \\ Yong $\mathrm{Li}^{3}$, \\ William L. Megginson ${ }^{4,3}$ \\ and Hao Zhang ${ }^{5}$ \\ ${ }^{1}$ Xiamen National Accounting Institute, \\ Xiamen 361005, China; ${ }^{2}$ School of Economics \\ and Finance, South China University of \\ Technology, Guangzhou 510006, China; ${ }^{3}$ School \\ of Banking and Finance, University of \\ International Business and Economics, \\ Beijing 100029, China; ${ }^{4}$ Michael F. Price College \\ Norman 73019, USA; ${ }^{5}$ School of Finance, \\ Guangdong University of Foreign Studies, \\ Guangzhou 510006, China
} \footnotetext{
of Business, University of Oklahoma,

Correspondence:

Y Li, School of Banking and Finance, University of International Business and Economics, Beijing 100029, China e-mail: yongli@uibe.edu.cn Correspondence:

H Zhang, School of Finance, Guangdong University of Foreign Studies,

Guangzhou 510006, China

e-mail: haozhang@gdufs.edu.cn
}

\section{CORRECTION TO: JOURNAL OF INTERNATIONAL BUSINESS STUDIES (2021) HTTPS://DOI.ORG/10.1057/S41267-021-00466-7}

Due to a typesetting mistake, the article was published with a missing affiliation for the author William L. Megginson. This author is affiliated with affiliation 3 and 4 . This was corrected now.

No other changes to the article have been made. We apologise for any inconvenience caused to our readers.

Publisher's Note Springer Nature remains neutral with regard to jurisdictional claims in published maps and institutional affiliations. 